\title{
El framing y la construcción de estrellato en la era digital. Estudio de caso: El mal querer de Rosalía en la prensa escrita española (2018-2020)
}

\section{Framing and production of stardom in the digital age. Case study: Rosalía's El Mal Querer in the Spanish written press (2018-2020)}

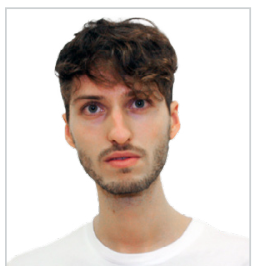

\begin{abstract}
Mateu Terrasa Rico. Graduado en Historia y Ciencias de la Música (USAL) y con máster en Periodismo Cultural por la Universidad CEU San Pablo. Profesor colaborador en el mismo máster impartiendo el Taller de Jazz desde el año 2017. Músico profesional. Actualmente IF del programa de doctorado en Comunicación Social (CEU-CEINDO) y becario FPU por la tesis La producción de estrellato en la era digital. Estudio de caso: El mal querer de Rosalía.

Universidad CEU San Pablo, Madrid, España

mateu.terrasarico@colaborador.ceu.es

ORCID: 0000-0001-7788-3006
\end{abstract}

Recibido: 26/11/2020 - Aceptado: 26/02/2021 - En edición: 26/03/2021 - Publicado: 14/06/2021 Resumen:

Aún no hallamos investigaciones académicas en torno a la figura de Rosalía. El estrellato en la música popular dentro del marco de la era digital, como fenómeno propio de las sociedades posmasivas, es una parcela científica inexplorada en nuestro país. Nuestro objetivo principal es analizar los frames generados por los cuatro principales medios de la prensa generalista nacional (El País, El Mundo, La Vanguardia y $A B C$ ) al rededor de la estrella catalana. Tras un análisis de framing narrativo y retórico de 331 artículos hemos hallado un total de 10 frames culturalmente imbuidos. Los resultados de la investigación muestran la presencia de frames y frames antagonistas dentro de los mismos medios, lo que hace patente la complejidad del fenómeno y el carácter polimórfico del estrellato en la era digital, así como las transformaciones que experimenta la identidad en la cultura globalizada.

\section{Palabras clave:}

Rosalía y El mal querer, framing narrativo y retórico; estrellato en la era digital; cultura digital y música popular; frames y prensa.
Received: 26/11/2020 - Accepted: 26/02/2021 - Early access: 26/03/2021 - Published: 14/06/2021 Abstract:

We still have not found academic research on the figure of Rosalia. Stardom in popular music within the framework of the digital age, as a phenomenon typical of post-massive societies, is an unexplored scientific realm in our country. Our main objective is to analyze the frames provided by the four main media agencies of the national general press (El País, El Mundo, La Vanguardia and ABC) around the Catalan star. After a narrative and rhetorical framing analysis of 331 articles, we have found a total of 10 culturally embedded frames. The results of the research show the presence of frames and counterframes within the same media, which makes clear the complexity of the phenomenon and the polymorphic nature of stardom in the digital age, as well as the transformations in identity in globalized culture.

\section{Keywords:}

Rosalía and El Mal Querer; narrative and rhetorical framing; stardom in the digital age; digital culture and popular music; frames and press.

Cómo citar este artículo:

Terrasa Rico, M. (2021). El framing y la construcción de estrellato en la era digital. Estudio de caso: El mal querer de Rosalía en la prensa escrita española (2018-2020). Doxa Comunicación, 32, pp. 381-404. 


\section{Introducción}

Proponemos a Rosalía como uno de los fenómenos de masas más relevante de la era digital en nuestro país. Tras la publicación y difusión de El mal querer (Sony) el 2 de noviembre de 2018, la artista catalana de música urbana, flamenco y pop consiguió encumbrarse como la personalidad más buscada en Google por la población española en 2018 ${ }^{1}$. Desde su concierto sorpresa en la plaza Colón de Madrid, pasando por su interpretación de Me quedo contigo en los Goya 2019 o su aparición en el filme de Almodóvar Dolor y gloria (2019), no hemos dejado de atestiguar su ubicuidad en la vida pública española y su consagración como fenómeno de masas global.

Enmarcado dentro de un proyecto de tesis doctoral en comunicación social y periodismo musical, este artículo se centra en el tratamiento periodístico de dicha figura desde el análisis de los frames generados por la prensa española escrita de referencia. Dado nuestro acercamiento a un fenómeno contemporáneo de gran alcance y rápido crecimiento ${ }^{2}$, esta constituye la primera aproximación académica a este novedoso y ramificado objeto de estudio. Aunque aún no hallamos bibliografía científica en torno al caso Rosalía ni sobre el estudio del estrellato en nuestro país, citamos dos excepciones pertenecientes al campo divulgativo/ensayístico: el libro La Rosalía. Ensayos sobre el buen querer (Carrión, 2021), aún inédito en el momento de escritura de este artículo, será publicado por Errata Naturae el 8 de marzo de 2021. Este volumen coordinado y orquestado por el crítico cultural Jorge Carrión, explora los diversos aspectos de la industria cultural y de la sociedad de posmasiva que ha removido el fenómeno de Rosalía. Por otro lado, el libro El Trap. Filosofía millennial para la crisis en España (2019) del filósofo Ernesto Castro dedica unas páginas al fenómeno Rosalía como manifestación flamencamp y su relación con el trap a modo de banda sonora de la crisis en España.

De la misma forma, la aplicación de la teoría del framing al estudio de la música popular, tanto en prensa generalista como en campos del periodismo musical, es inexistente en el ámbito hispanohablante e igualmente escasa a nivel internacional (McClain, 2016; McClain y Lascity, 2019). Como referencia de esta metodología podemos tomar el análisis de framing narrativo aplicado a la representación mediática de temas como la demencia, donde se muestra la presencia de frames culturalmente imbuidos que refuerzan (frames dominantes) o rechazan (counter-frames) la estigmatización de las enfermedades mentales a través de valores socialmente compartidos como la realización personal, la autonomía o el individualismo (Van Gorp y Vercruysse, 2012). En el caso del framing desde la prensa internacional de movimientos de género como \#MeToo, también hallamos la presencia de arquetipos, valores y metáforas relevantes a la hora de describir personalidades públicas y su papel social: "Los frames de objetivos y agencia crean la imagen de mujeres fuertes con una causa, al contrario del clásico frame de victimización aplicado a las víctimas de la violencia sexual, el cual retrata a una persona débil" (Erickson, 2019: 8). Estos estudios mencionados constituyen referentes metodológicos y conceptuales que conducen este pionero análisis de framing narrativo y retórico aplicado a la representación periodística del estrellato en música popular.

1 Información extraída de Google Trends: https://trends.google.es/trends/yis/2018/ES/

2 Es remarcable la viralización del fenómeno desde el lanzamiento del single Malamente y su videoclip realizado por la productora Canadá, publicado el 30 de mayo de 2018 . 
Así mismo, el estudio del estrellato en música popular a través de la colección de ensayos titulada "Popular Music, Stars and Stardom" (Loy, Rickwood, Bennett, 2018) contribuye a la disección académica de estrellas en el contexto de la era digital. Debido a la proximidad con el universo Rosalía, resulta de enorme interés el capítulo "Intimacy, Authenticity and 'Worlding' in Beyoncés Star Project” (Macrossan, 2018), donde se exploran las nociones musicales, narrativas, estéticas y conceptuales que conforman el universo generado por la cantante Beyoncé en el álbum Lemonade (2016). Siguiendo estos preceptos, resulta evidente la necesidad de un enfoque transversal en la investigación del campo del estrellato y la cultura celebrity (Marshall y Redmond, 2015). De tal forma, disciplinas como los estudios culturales y la conceptualización de la identidad como proceso discursivo e histórico (Hall, 2003), la construcción de la identidad colectiva a través de la práctica musical (Firth, 1996; Martí, 2000) o el racismo implícito en la diferenciación étnica incorporada por colectivos excluidos (Mbembe, 2016), serán aportaciones enriquecedoras en la formación de nuestro aparato conceptual.

\subsection{Estrellato y música popular en la era digital}

Definimos el estrellato como el reconocimiento colectivo que recibe un individuo sobresaliente en determinado campo socio-cultural (Loy et al., 2018). Pudiendo darse en áreas como el deporte, la cocina, el cine, la política o la música popular, en el caso de esta investigación, distinguimos dicho fenómeno del concepto de "celebrity", el cual alude a una fama más inmediata y efímera que no conlleva necesariamente habilidades extraordinarias (Rojek, 2001; Busquet-Duran, 2012). Asumimos que el estrellato se da dentro unas condiciones necesarias, pues se ubica dentro de una jerarquía de talento (Rosen, 1981), es mediado por los hábitos de capital de consumo del público (Adler, 2006) y es un fenómeno propio de una cultura de masas donde se favorece un lenguaje globalizado y destradicionalizado (Cusack, 2011).

Más allá de la cultura de masas, a través del ecosistema digitalizado asistimos a un cambio en los paradigmas de comunicación modernos que nos acercan a un modelo de cultura interactiva o posmasiva (Rizo García, 2013). En este marco las relaciones entre estrellas y audiencias se ven transformadas, donde se disuelve la relación asimétrica de idolatría por formas de interacción más directas y comprometidas (Marshall, 2010). En contraposición al espectador pasivo retratado por la Escuela de Frankfurt (Horkheimer y Adorno, 1944/1988), el usuario es el principal agente responsable del auge de los nuevos escenarios en red interactivos: el fenómeno broadcast yourself ${ }^{3}$ y los blogs colaborativos, la dinámica no lineal del hipervínculo y el hipertexto, las formas de comunicación interpersonal/grupal mediante mensajería instantánea, la autoproducción creativa, las plataformas de streaming personalizables o la creación de comunidades alrededor de personalidades conspicuas. Es en este contexto donde el star-system tan solo logra expandir su poder evangelizador a un ámbito global e hiperconectado con mayor velocidad. Esto se debe a que las estrellas, investidas de autoridad carismática ${ }^{4}$, gozan de "una posición privilegiada en la definición de roles y arquetipos sociales, y esto tiene consecuencias en cómo las personas creen que pueden y deben comportarse” (Dyer, 1998: 8).

3 Broadcast yourself ("transmite tú mismo"), es el lema de la empresa y plataforma de streaming de video YouTube fundada en 2005.

4 Tal y como explica Max Weber en Economía y Sociedad (1922/2002: 172-173), la dominación carismática, de orígenes religiosos, parte de unas características personales y extraordinarias procedentes de un sujeto singular o heroico. Este tipo de autoridad se distingue de otras clases de dominación -como son como la tradicional o la burocrática-, pues son los individuos quienes escogen a la figura a encumbrar en base a sus cualidades únicas (no hay una inercia u obligación contractual como sí sucede en los otros tipos de dominación). En última instancia, dicho tipo de poder es inestable, pues se halla investido por el apoyo de los acólitos y la posibilidad de su volatilidad. 
En su función de receptáculos semiótico-culturales (Dyer, 1998) y somático-emocionales (Redmond, 2015), estas figuras públicas catalizan y reflejan complejos procesos por los que atraviesa la identidad contemporánea. En el caso de Rosalía: la colisión entre tradición y modernidad, la (in)visibilidad femenina en la industria musical o las tensiones entre lo local y global en la era digital son buena muestra de ello (véase el apartado 3. Resultados). Sea a través de la mímesis de sus cualidades extraordinarias o del escarmiento a partir de sus tragedias, las estrellas y el conjunto del star-system actúan como una suerte de mitología contemporánea que, al igual que sucedía con los héroes de las civilizaciones antiguas, satisfacen las necesidades afectivo-míticas del pueblo (Morin, 1972; Busquet-Duran, 2012).

En el caso de la música popular y según datos del VEVO Music Fan Report: The Millennial Fan Tribes (2015), el 51\% de los sujetos encuestados escoge a las celebrities musicales como referentes vitales que ostentan las mayores cotas de talento percibido. Así mismo, la música corona el puesto de contenido multimedia más compartido en redes sociales por encima de la televisión, el cine, el humor o los deportes) (VEVO, 2015). Es en el contexto digitalizado más reciente que hemos presenciado la explosión de la música urbana, así como la globalización de lo exótico a través de lo latino y del pop flamenco de Rosalía. Dicha situación es indiscutiblemente favorable para los propios artistas, donde el ordenador se encumbra como el metainstrumento que controla todas las fases de creación (composición, grabación, producción, masterización y difusión) (Márquez, 2010). La capacidad de libertad y auto-producción que esta tecnología permite nos acerca a una concepción del artista mucho más autónoma, lo cual tiene también consecuencias sobre la difusión de su obra: "La inmediatez y repercusión global de la tecnología y las redes sociales contemporáneas permiten mayores oportunidades para que los músicos populares establezcan una audiencia fiel y luego operen de manera más independiente respecto a las directrices de la industria (Loy et al., 2018: 11).

\subsection{El framing narrativo y retórico en el análisis de la prensa escrita}

Es innegable la prominencia internacional que la teoría del framing ha cobrado en los estudios de comunicación en las dos últimas décadas (Sádaba, 2001; Sabrina Koziner, 2013). Bryant y Miron (2004: 693) incluyeron el framing como una de las "26 teorías más distinguidas" en el campo de la comunicación. Por otro lado, desde que Robert Entman (1993: 51) evidenciara el "paradigma fragmentado" de esta teoría, en las últimas dos décadas hemos asistido a una preocupación y esfuerzo en la solidificación metodológica del framing (Tankard, 2001; Sádaba, 2001; Reese, 2001; Van Gorp, 2010; Van Gorp y Vercruysse, 2012).

Al orientar esta teoría, de orígenes antropológico-sociológicos (Bateson, 1972/1993; Goffman, 1972/1986), hacia la investigación en comunicación y medios "abrimos un importante campo de análisis: en concreto, ¿ cómo son ciertos temas construidos, ciertos discursos estructurados y ciertos significados desarrollados?” (Reese 2001: 7). De la multiplicidad de significados y propuestas que la teoría ha tomado en las últimas décadas, nos resulta enormemente útil la definición propuesta por Stephen Reese de los frames como "principios organizativos socialmente compartidos y persistentes en el tiempo, que funcionan simbólicamente para estructurar el mundo social de modo significativo (2001: 11). Este tipo de definición parte de la concepción del frame como dispositivo que interactúa con la realidad social, la cual consideramos, bajo la visión del construccionismo social, un relato mediado y creado por actores que manejan información compartida (Gamson y Modigliani, 1989). 
Así mismo, la definición de Reese contempla la noción de persistencia, la cual tiene como corolario considerar a los frames como estructuras sociocognitivas autónomas que trascienden al propio individuo y su temporalidad (Polletta, 2004). Debemos considerar que el frame no se encuentra únicamente en el contenido manifiesto del texto, sino en las tensiones y relaciones del núcleo texto-sujeto-cultura (Entman, 1993; Sádaba, 2001). Dado que, como hemos mencionado, las estrellas actúan como receptáculos semiótico-culturales (Dyer, 1998) y somático-emocionales (Redmond, 2015) del colectivo social que las engendra, necesitamos una herramienta de análisis sensible al contenido simbólico de dichas manifestaciones. La capacidad del framing narrativo y retórico a la hora de extraer significados profundos y desvelar estructuras socioculturales latentes resulta idónea a la hora de abordar el fenómeno Rosalía y su reflejo mediático como objeto de estudio ramificado.

Dada la novedad del objeto de estudio, esta investigación toma un carácter exploratorio y, necesariamente, debe acotar su universo de acción. Nuestra elección a la hora de analizar la prensa escrita española de referencia reside en la enorme influencia del periódico sobre los formatos multimedia: "Debido a la mayor experiencia en el mundo y en los sistemas de comunicación" (Cabrera González, 2001: 1), observamos como "los periódicos proveen un entorno de credibilidad y proximidad que la mayoría de los demás medios no pueden brindar" (Solís Baena, 2016: 177). Esta posición referente de la prensa tradicional se explica por tres factores: i) "La dotación de contenidos informativos". ii) La presencia de "personal cualificado". iii) El mantenimiento de una "estructura organizativa determinada” (Cabrera González, 2001: 1). Así mismo, en el marco de la construcción de estrellato en la era digital, el fenómeno de la convergencia de medios (Jenkins, 2006) provoca que el contenido entre prensa escrita y digital, y el de otros medios como blogs, podcast o redes sociales, acabe cruzándose. Esto asegura que el análisis de nuestra muestra no constituya una realidad aislada, sino que, por el contrario, se asiente en una realidad intertextual viva donde el diálogo continuo (y por lo tanto la presencia de frames) entre el periódico y el resto de formatos constituya una muestra representativa y pertinente del universo que tratamos de comprender. Según este marco conceptual formulamos las siguientes hipótesis:

- Hipótesis 1 (H1): Los frames producidos en torno a Rosalía nos ayudan a comprender y configurar dicho fenómeno.

- Hipótesis 2 (H2): El fenómeno Rosalía refleja los procesos socioculturales que transitamos como civilización en la era digital.

Nuestros objetivos derivados son:

- O1: Extraer los frames culturalmente imbuidos utilizados por cada medio.

- O2: Relacionar cada frame, en su carácter culturalmente imbuido, con el sustrato de valores, narrativas, estereotipos, arquetipos y metáforas colectivamente compartidos. 


\section{Metodología}

\subsection{Muestra}

Este corpus ha sido seleccionado a través del buscador académico MyNews, dentro del cual hemos colocado como criterio de búsqueda "Rosalía" y su presencia en el título o subtítulos de los cuatro medios seleccionados. La búsqueda se halla comprendida entre el 1 de enero de 2018 (inicio del año del fenómeno) hasta el 15 de marzo de 2020 (cercanía de los Grammy 2020 e inicio de la crisis del COVID-19). Hemos escogido los cuatro principales medios generalistas de mayor tirada nacional y sus respectivos suplementos de contenido cultural: El País (junto a Babelia y El País semanal), El Mundo (junto a El Cultural, La esfera de papel, Yo Dona y Metrópoli), ABC (junto a ABC Cultural) y La Vanguardia (junto a Cultura/s) $)^{5}$.

Del total de 331 artículos obtenidos extraemos las siguientes cifras:

Tabla 1.

\begin{tabular}{|c|c|}
\hline $1-$ El País $=64$ artículos & $2-$ El Mundo=93 artículos \\
\hline $3-$ La Vanguardia $=71$ artículos. & $4-A B C=103$ artículos \\
\hline
\end{tabular}

Fuente: elaboración propia (tabla y gráfico)

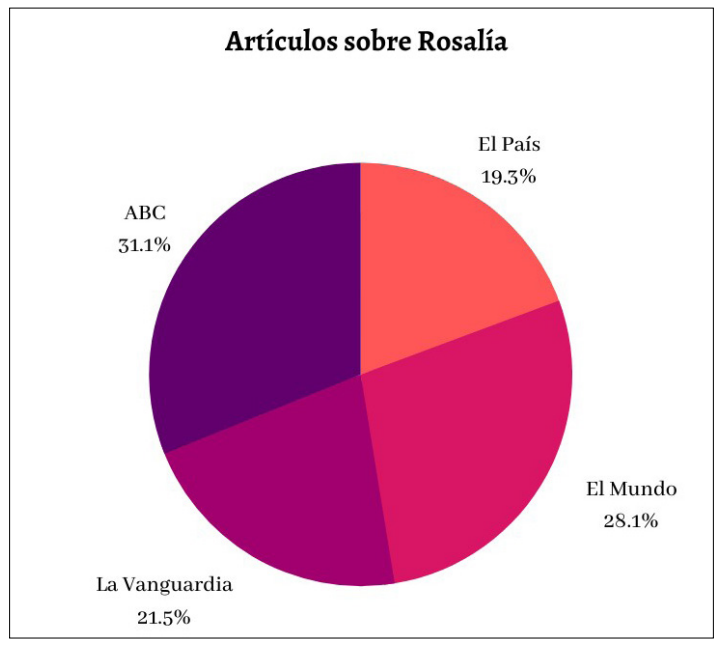

Fuente: elaboración propia (tabla y gráfico)

5 Los criterios de selección de estos cuatros medios es su volumen de lectores: quitando la prensa deportiva (Marcay As), los cuatro medios seleccionados representan los cuatro primeros puestos de mayor tirada nacional. Además, la variedad ideológica de las cuatro fuentes nos permite una visión más ecuánime acerca de la visión del fenómeno Rosalía en España. Fuente: https://es.statista.com/estadisticas/476795/periodicos-diarios-mas-leidos-enespana/ 


\subsection{Procedimiento}

Nuestra propuesta metodológica procederá de la aleación de tres vertientes del análisis de framing:

a) El análisis narrativo propuesto por Baldwin Van Gorp (2010; Van Gorp y Vercruysse, 2012), procedimiento que contempla la noción de frames culturalmente imbuidos (culturally embedded frames) como "marcos de noticias que expresan nociones culturalmente compartidas con significado simbólico, como estereotipos, valores, arquetipos, mitos y narraciones." (Van Gorp, 2010: 2). Buscaremos la relación de cada encuadre con estructuras más profundas de pensamiento colectivo (tema cultural), lo cual nos llevará a conectar el tema de una noticia y su tratamiento con valores, narrativas y aspectos fundacionales de nuestra cultura (O2).

b) El análisis retórico propuesto por Jim Kuypers (2010), el cual contempla la necesaria integración de la personalidad del investigador dentro del trabajo hermenéutico, lo que posibilita el análisis crítico de los frames y los fenómenos de alta carga simbólica (Igartua, Muñiz y Cheng, 2005). Dado que la investigación cualitativa se halla profundamente ligada a una posición filosófica (Vasilachis de Gialdino, 2006), el análisis retórico considera fundamental la argumentación y justificación de los procesos metodológicos, analíticos e interpretativos. Mediante este enfoque retórico aseguramos la rigurosidad y validez interpretativa que la investigación cualitativa debe ostentar a fin de aportar datos generalizables o extrapolables.

c) La visión de cada frame como un contenedor simbólico con sentido narrativo y guiado por las funciones del frame propuestas por Robert Entman (1993): definición de tema, causas, evaluación moral y solución. Según el autor, el framing consiste en "seleccionar determinados aspectos de una realidad percibida y enfatizarlos dentro de un (con)texto comunicativo, de tal forma que esto estimule una definición del problema particular, una interpretación de causa, una evaluación moral y una posible solución" (Entman (1993: 52). El lector muchas veces no es consciente de este tratamiento de la información que, en última instancia, tiene el fin de influir sobre su propia percepción de la noticia y de la realidad social (Kuypers, 2010). Dado el carácter latente de los frames (Igartua, Muñiz y Cheng, 2005), debemos buscar indicadores manifiestos que señalen su presencia. Estos indicadores reciben el nombre de elementos de frame (framing devices), entre los cuales encontramos: títulos, subtítulos, imágenes, citas, párrafos finales, argumentos recurrentes, figuras retóricas, frases hechas o expresiones, elementos paratextuales, la elección de vocabulario, la cita de actores relacionados y el uso de descripciones (Gamson y Modigliani, 1989; Entman, 1993; Tankard, 2001; Van Gorp, 2010).

Basados en este marco, proponemos un análisis inductivo que culminará con la elaboración de una matriz para cada frame. Dado que "la intención de un análisis de encuadre inductivo es reconstruir los marcos que son útiles para definir cierto tema" (Van Gorp 2010: 12), nuestro procedimiento inductivo se guiará por tres fases propuestas por Strauss y Corbin (1990), las cuales se hallan basadas en los preceptos de la teoría fundamentada (grounded theory) y son ampliadas por Van Gorp (2010):

1. - Codificación abierta: examinamos los textos sin "un instrumento de codificación previo" (Van Gorp, 2010: 15), identificando posibles unidades de elementos de frame. 
2. - Codificación axial: A continuación agrupamos cada elemento de frame con "similitudes, diferencias y contrastes entre los elementos identificados" (Ibíd.: 15), formando categorías conceptuales más grandes.

3. - Codificación selectiva: Incluiremos los grupos de elementos de frame dentro del sentido narrativo de las siguientes categorías de la matriz:

1) Tema cultural.

2) Definición de tema (problemático o no ${ }^{6}$ )

3) Causas

4) Evaluación moral

5) Solución

6) Elementos de framing

7) Ejemplos (citas textuales).

El uso de matriz nos permitirá mayor sistematización, claridad y replicabilidad a la hora de generar los frames (Tankard, 2001). Dado que nos hallamos ante un objeto de alta carga simbólica, la metodología inductiva se presenta idónea y sensible al contexto sociocultural que nuestro análisis debe integrar. Por otro lado, la fortaleza de la teoría fundamentada (grounded theory) radica en "la codificación abierta y su uso de preguntas y comparaciones constantes que permite a los investigadores romper la subjetividad y el sesgo. Lo que obliga a las nociones e ideas preconcebidas a examinarse contra los datos" (Strauss y Corbin, 1990: 13). La siguiente tabla es un ejemplo de la matriz utilizada en este proceso metodológico.

6 Jiménez-Yánez (2000: 58) define el tema (issue) como “el sujeto del pensamiento expresado" en una serie de textos o noticias; añadiendo la distinción de tema problemático como "un asunto que crea debate social y resulta conflictivo" (Ibídem: 58). En el tema problemático será esencial la propuesta de solución, mientras que en el tema (issue) hay una prevalente ausencia de conflicto y, por lo tanto, el periodista no emitirá una intención de solución. 
Tabla 2

\begin{tabular}{|c|c|c|c|c|c|c|}
\hline Imagen cultural & $\begin{array}{l}\text { Definición del } \\
\text { tema }\end{array}$ & Causas & $\begin{array}{c}\text { Evaluación } \\
\text { Moral }\end{array}$ & Solución & $\begin{array}{l}\text { Elementos de } \\
\text { framing }\end{array}$ & Ejemplos \\
\hline \multicolumn{7}{|c|}{ 3. - El invasor (la muerte del flamenco) [tema problemático] [counter-frame de 4. - Universalismo cultural] } \\
\hline $\begin{array}{l}\text { La tradición/ } \\
\text { va-lores de un } \\
\text { grupo es ame- } \\
\text { nazada por la fi- } \\
\text { gura del invasor. } \\
\text { Hay una llama- } \\
\text { da a la defensa: } \\
\text { Nosotros versus } \\
\text { lo extraño. }\end{array}$ & $\begin{array}{l}\text { La obra de can- } \\
\text { tantes como } \\
\text { Rosalía y El } \\
\text { Niño de Elche } \\
\text { es considerada } \\
\text { música fla- } \\
\text { menca por las } \\
\text { audiencias. Los } \\
\text { expertos ad- } \\
\text { vierten como la } \\
\text { música de estos } \\
\text { artistas no entra } \\
\text { dentro de los } \\
\text { parámetros de } \\
\text { lo jondo. }\end{array}$ & $\begin{array}{l}\text { Rosalía es can- } \\
\text { tante, no can- } \\
\text { taora. La artista } \\
\text { toma elementos } \\
\text { del flamenco y } \\
\text { los traslada al } \\
\text { pop. Este equí- } \\
\text { voco genera } \\
\text { confusión en } \\
\text { el público no } \\
\text { familiarizado. }\end{array}$ & $\begin{array}{l}\text { Estos artistas } \\
\text { achacan una } \\
\text { falta de conoci- } \\
\text { miento y habi- } \\
\text { lidad respecto } \\
\text { a la ejecución } \\
\text { de las reglas del } \\
\text { flamenco, da- } \\
\text { ñando así al gé- } \\
\text { nero. Rosalía se } \\
\text { mueve dentro } \\
\text { de la ambigüe- } \\
\text { dad, despista a } \\
\text { las audiencias y } \\
\text { degrada el cante } \\
\text { en una solución } \\
\text { puramente } \\
\text { melódica. }\end{array}$ & $\begin{array}{l}\text { Hay una lla- } \\
\text { mada a pro- } \\
\text { teger frente al } \\
\text { intrusismo de } \\
\text { aquellos artistas } \\
\text { que no cumplen } \\
\text { los estándares } \\
\text { de calidad del } \\
\text { género. }\end{array}$ & $\begin{array}{l}\text { Elección de } \\
\text { vocabulario: } \\
\text { Intrusos, con- } \\
\text { fusión, música } \\
\text { aflamencada, } \\
\text { engañoso, de- } \\
\text { gradar, apropia- } \\
\text { ción, polémica. } \\
\text { Metáforas y ex- } \\
\text { presiones: Las } \\
\text { reglas del géne- } \\
\text { ro / se lo lleva a } \\
\text { su terreno. } \\
\text { Actores rela- } \\
\text { cionados con } \\
\text { el tema proble- } \\
\text { mático: Niño de } \\
\text { Elche, Pedro G. } \\
\text { Romero, Israel } \\
\text { Galván; “los } \\
\text { 'falsos' sabios". }\end{array}$ & $\begin{array}{l}\text { "Es una can- } \\
\text { tante que utili- } \\
\text { za el repertorio } \\
\text { flamenco para } \\
\text { llevárselo al } \\
\text { pop, ya que no } \\
\text { cumple las re- } \\
\text { glas del género } \\
\text { y desvirtúa la } \\
\text { esencia jonda } \\
\text { de los cantes" } \\
\text { (García Reyes, } \\
A B C, 25 \text { de } \\
\text { noviembre de } \\
\text { 2018). }\end{array}$ \\
\hline
\end{tabular}

Fuente: elaboración propia 


\section{Resultados}

Exponemos la lista total de frames que hemos obtenido en cada medio y su relación con el contexto en el que se hallan culturalmente imbuidos $(\mathrm{O} 2)$ :

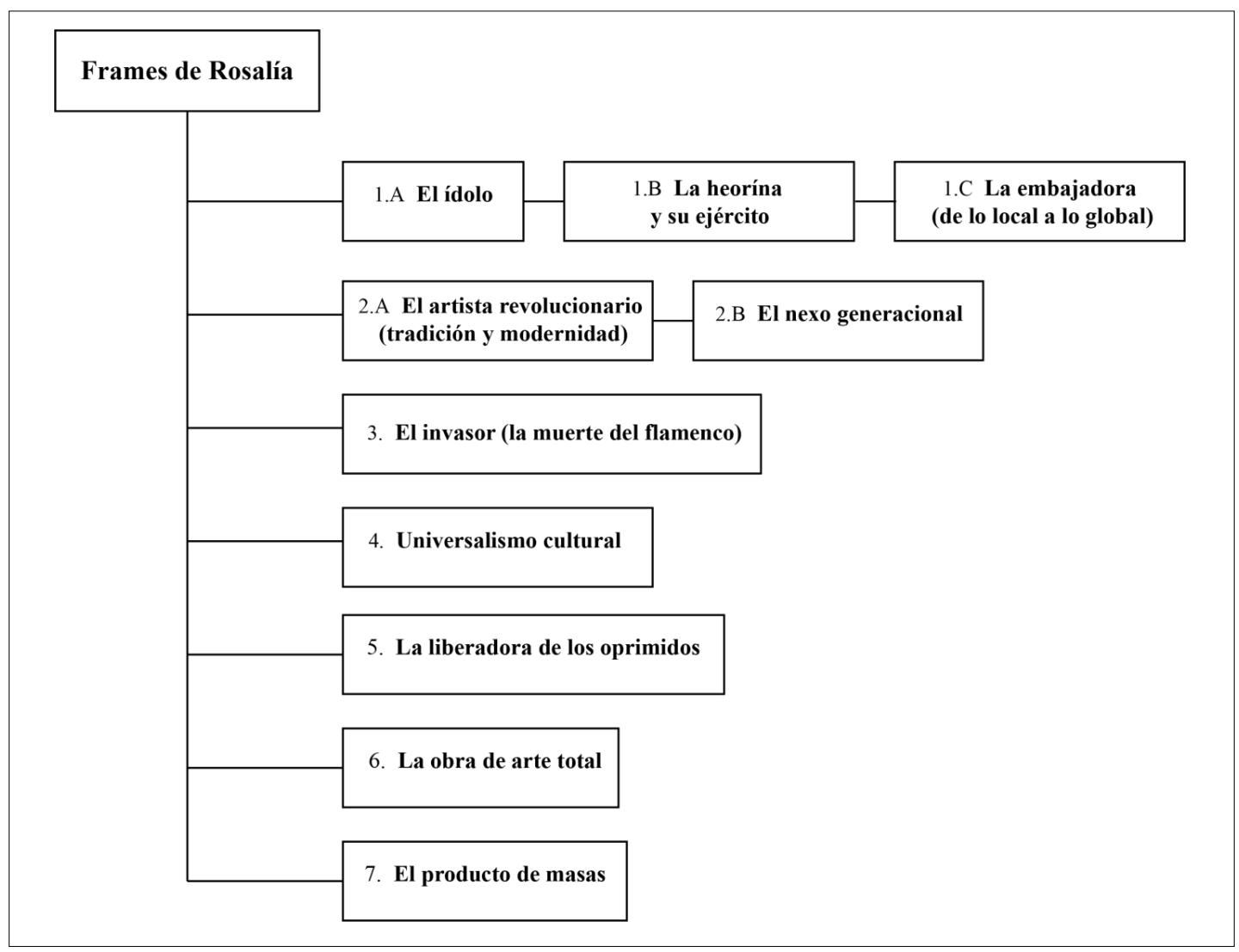

Fuente: elaboración propia

\section{A - El ídolo}

\section{Presente en: El País / El Mundo / La Vanguardia / ABC}

Este frame define el tema del estrellato y el boom mediático surgido tras El mal querer mediante la utilización de un encuadre religioso: una figura de adoración o divinidad (la artista catalana) provoca una reacción de idolatría colectiva (el fenómeno fan; los "rosaliebers") en el marco de una religión (el pop y la cultura maisntream). Las siguientes frases y 
expresiones son ejemplos de dicho frame: "La joven mesías del chándal " (Belmonte, $A B C, 5$ de febrero de 2019), "Una diosa contemporánea” (Álvarez, La Vanguardia, 14 de diciembre de 2019), "No necesita abrir la boca para tener a sus pies a la trupe de «rosaliebers»" (Higuera, $A B C, 17$ de junio de 2019), "En los libros sobre historia de la música la marca Rosalía ya está patentada" (Arbat, La Vanguardia, 28 de agosto de 2019a), "Convierte en oro todo lo que toca" (Domènech, $L a$ Vanguardia, 28 de agosto de 2019b), "La aristocracia del pop" (ABC, 3 de noviembre de 2019), y "Con una garganta capaz de engatusar a las masas” (Rigalt, El Mundo, 10 de febrero 2019).

La representación del estrellato en música popular a través de un frame religioso es sintomático de cómo nos hallamos ante un objeto de estudio plenamente posmoderno: "El pop como fenómeno transversal y unificador" (Morán, $A B C, 8$ de diciembre de 2019), se torna la nueva religión de las masas. Las estrellas y celebrities sustituyen a los héroes, santos y demás figuras de adoración, siendo el estrellato la nueva "religión embrionaria" y moderno parnaso al que aspirar (Morin, 1972: 23). En palabras de TvBoy, el artista siciliano callejero que realizó una pintura mural de Santa Rosalía en el Fossar de les Moreres:

He titulado la obra Santa Rosalía para que el público reflexione sobre la idolatría y el culto a los iconos del espectáculo en nuestra sociedad contemporánea. Antes el objeto de culto eran los iconos religiosos y ahora son las estrellas de la música y los influencers. Por eso en este mural aparece la nueva estrella internacional del flamenco pop a la que he querido caracterizar caracteriza como Santa Rosalía de Palermo, la patrona de mi ciudad natal (TvBoy citado en La Vanguardia, 10 de enero de 2019).

\section{B - La heroína y su ejército [counter-frame de "8. - El producto de masas"]}

\section{Presente en: El País / El Mundo / La Vanguardia / ABC}

La metáfora resulta el recurso retórico y atajo de pensamiento más directo a la hora de ahondar en formas de pensamiento colectivas (Lakoff y Johnson, 1981), siendo metáforas como la escalada a la cima, la conquista de ciudades o el acto de arrasar festivales ejemplos de la consecución de valores deseados como el éxito social, la visibilidad mediática o la realización profesional del individuo en la cúspide de su carrera. Bajo este frame, Rosalía encarna dichos ideales que, a su vez, son sublimados a través metáforas belicistas para enfatizar el carácter heroico/modélico de dichas actitudes: el esfuerzo, la disciplina, el liderazgo o la entrega total al trabajo son actitudes reflejadas en frases como "no tuve una adolescencia normal por entregarme al flamenco" (Gil, El Mundo - Papel, 30 de octubre de 2018) o "ha peleado por el éxito" (Serrano, $A B C, 31$ de agosto de 2019).

En este mismo sentido, la noción del "nutrido y bien armado equipo" (Serrano, $A B C, 31$ de agosto de 2019) de profesionales capitaneado por Rosalía evoca valores como la camaradería, la realización y la cooperación colectiva sintetizada bajo la frase popular de "la unión hace la fuerza". Esta dinámica de colaboración es reflejo del fenómeno conocido como hipermediación, bajo el cual asistimos a una creciente involucración de más intermediarios en todos los procesos de online debido a la creciente complejidad del entorno y las transacciones digitales (Carr, 2000). En este sentido, el holístico equipo de Rosalía refleja esta creciente hipermediación y especialización donde, citando algunos ejemplos, encontramos a Rebeca León (booking manager), su hermana Pili Vila (asistente de estilismo y community manager), su madre Pilar 
Tobella (encargada de la marca Rosalía), Pablo Díez Reixa “El Guincho” (productor), Jaycen Joshua (mezclador) o Charm La’Donna (coreógrafa). En definitiva, con la imagen de la heroína y su ejército este frame culturalmente imbuido plantea como "detrás del ascenso meteórico de la cantante catalana hay todo un equipo de managers, productores, compositores, coreógrafos y estilistas que le han ayudado a conquistar la industria de la música. El ejército con el que Rosalía ha conquistado el éxito global" (Serrano, $A B C, 31-8-2019$ ).

\section{C - La embajadora (de lo local a lo global)}

Presente en: El País / El Mundo / La Vanguardia / ABC

Este frame retrata la figura de una embajadora representante de una civilización en el extranjero, exportando dicha cultura allende sus límites y fronteras. Rosalía, la española más internacional desde Julio Iglesias, es evaluada como "nuestra mejor embajadora flamenco-reguetonera" (Serrano, $A B C$, 12 de noviembre de 2019) y como "prima donna cañí" (Lucía Ramis Citado en Peirón, La Vanguardia, 17 de noviembre de 2018). De tal forma, este frame se revela con la utilización de contrastes entre aspectos idiosincráticos (lo local) y la cultura estadounidense (equiparada con la cultura global):

Tabla 3.

\begin{tabular}{|c|c|}
\hline Local & Global \\
\hline San Esteve de Sesrovires (ciudad natal de Rosalía) & La Gran Manzana \\
\hline Quejío, voz desnuda de acompañamiento, flamenco catalán & MTV, estadounidense, pop \\
\hline Banderas españolas ondeando & Festival Lollapalooza de Chicago \\
\hline Ya tiene su propio caganer & Alcance planetario \\
\hline
\end{tabular}

Fuente: elaboración propia

Dicho encuadre busca alejar al lector de una posición pesimista, como podrían ser las críticas a las dinámicas etnocidas de la globalización (Moreno, 2002), para acercarnos a la internacionalización de la artista como un valor deseado. En este sentido, ella es uno de los agentes encargados de expandir la cultura española y flamenca en el ámbito global: "Yo vengo de Barcelona y estoy tan feliz de estar aquí y representar a mi país y a mi cultura” (Rosalía citado en Domènech, La Vanguardia, 28 de agosto 2019). Bajo esta evaluación moral, la glocalización es asumida como el triunfo de "la reafirmación identitaria de los colectivos humanos, la localización” (Martí, 2000: 55) en un entorno global y digitalizado. En este contexto Rosalía se alza como "la primera gran diva de pop global nacida en la piel de toro" (Serrano, $A B C, 30$ de octubre 2018), siendo un símbolo del poder de las identidades en un mundo digital y globalizado (Castells, 1997).

7 Declaraciones pronunciadas en los premios MTV Music 2019, evento celebrado en Nueva Jersey (Estados Unidos) el 26 de agosto del mismo año. 


\section{A - El artista revolucionario (tradición y modernidad) [Tema problemático] [counter-frame de “3. - El invasor”]:}

Presente en: El País / El Mundo / La Vanguardia / ABC

Este frame culturalmente imbuido nos presenta a la artista como una vidente con el poder de ver más allá, capaz de avanzar la sensibilidad colectiva de la civilización. La figura del artista revolucionario es un arquetipo alimentado por las vanguardias artísticas de principios del siglo XX (especialmente por el carácter inconformista del futurismo, el cubismo y la abstracción). Dicha figura revolucionaria fue extendida al imaginario colectivo a través de la pluma del pintor ruso Wassily Kandinsky en su obra De los espiritual en el arte:

Entonces aparece un hombre parecido en todo a nosotros, pero que tiene dentro de sí una fuerza visionaria y misteriosa. El observa y enseña. Por momentos desea liberarse de ese don superior que a menudo es una pesada cruz. Pero no puede. A pesar de las burlas y los odios, lleva hacia adelante y hacia arriba el pesado y reacio carro de la Humanidad que se detiene entre las piedras (Kandinsky, 1911/1979: 13).

En términos académicos, esta forma de avance en determinado oficio o campo del saber tiene el nombre de propulsión artística (Sternberg, Kaufman y Pretz, 2001; Harrison, 2018). Al amparo de dicha idea, Rosalía encarna el modelo de síntesis o integración (integration), el cual "representa un intento de avanzar determinado campo juntando aspectos de dos o más tradiciones que anteriormente eran concebidas como distintas e incluso opuestas” (Sternberg et al., 2001: 80). Este impulso de síntesis es representado mediante el uso de contrastes entre los conceptos de tradición (el carácter orgánico del arte jondo) y modernidad (el aspecto tecnológico de la música popular urbana):

Tabla 4 .

\begin{tabular}{|l|l|l|}
\hline $\begin{array}{l}\text { Tradición, tangos, el duende, palos, bulerías, cantes } \\
\text { vetustos, cante, seguiriyas, cantaora, quejí, baile } \\
\text { flamenco, paya, vestido con flecos y volantes. }\end{array}$ & $\begin{array}{l}\text { Versus } \\
\text { Contemporáneo, sample, autotune, pistas } \\
\text { pregrabadas, subgraves, electrónica, trap, ruido de } \\
\text { motores y fenazos de coches, experimental, adidas } \\
\text { con plataforma. }\end{array}$ \\
\hline
\end{tabular}

Fuente: elaboración propia

De tal forma, este frame actúa como frame antagonista (counter-frame) del El invasor (p. 16). En este caso, el mecanismo que permite la creación de "la identidad cultural supone una mediación incesante entre tradición y renovación, permanencia y transformación, emoción y conocimiento" (Hormigos, 2010: 94). Visión que es secundada desde el medio $A B C$ de manera manifiesta: "Un arte que se reinventa con ella y que entra en la época 2.0. Bienvenidos al flamenco del siglo XXI de la mano de una estrella global que trasciende géneros. Tradición y vanguardia. Por muchos años" (Escribano, $A B C$, 11 de diciembre de 2019). 


\section{B - El nexo generacional}

\section{Presente en: El País / El Mundo / La Vanguardia / ABC}

Además de suponer un avance en su campo creativo (frame 2 A El artista revolucionario [tradición y modernidad]), la artista catalana, bajo la visión de este frame, cumple la función de puente generacional entre el arte jondo y la generación millennial (1982-2004) y centennial (2005-presente). Bautizado como el “El cante jondo intergeneracional” (Neira, El País, 18 de enero de 2018), su obra y su figura cumplen el papel de nexo entre dos públicos históricamente divididos (el flamenco y el mainstream), unión que "ha logrado que las nuevas generaciones conecten con una música reservada hasta ahora para los puristas" (El Mundo, 5 de marzo de 2018).

Esta misma función es representada por otras bandas del pasado musical español como son Pata Negra, Kiko Veneno, Camarón de la Isla o Ketama, quienes introdujeron a los Baby boomer (1943-1960) y la Generación X (1961-1981) ${ }^{8}$ al arte jondo. En este caso, Rosalía es un nuevo eslabón que introduce masivamente el flamenco de manera intergeneracional y lo proyecta al ámbito global: «Es hija de su tiempo, tiene 25 años y cientos de miles de seguidores en Instagram, pero su música atrae por igual a millennials que por primera vez se han acercado a los ecos flamencos y a veteranos con amplio bagaje musical" (López Enano, El País - Semanal, 16 de septiembre de 2018). De tal forma, esta función de nexo es reconocida como un logro importante en la historia musical de nuestro país: "Lograr la atención masiva y devota para una canción flamenca sin aliño contemporáneo ni trucos de producción ni jaleos tecnificados, sea un triunfo más importante que la respuesta febril a los temas clave de El mal querer" (concierto de Rosalía en el BBK 2019, Bilbao) (Benito, ABC , 13 de julio de 2019).

\section{3. - El invasor (la muerte del flamenco) [tema problemático] [counter-frame de “4. - Universalismo cultural”]}

\section{Presente en: El Mundo / $A B C$}

Este frame retrata a la artista catalana bajo el arquetipo del invasor (el otro; "los falsos revolucionarios del flamenco") que amenaza a un colectivo (nosotros; la integridad y evolución del arte jondo). Dicha evaluación moral posiciona a la artista catalana dentro de un exogrupo bajo la etiqueta de "intrusos" (García Reyes, $A B C$, 2 de octubre 2018) o "infiltrados que van por la vida de transgresores” (García Reyes, $A B C$, 2 de octubre 2018). En este exogrupo de actores mencionados figuran El Niño de Elche, el bailaor Israel Galván, el intelectual Pedro G. Romero o la propia Rosalía, conformando todos ellos la arquetípica figura de El invasor que, en este caso, “abarata” la "tradición jonda” (García Reyes, $A B C$, 30 de septiembre de 2018). Respecto a los elementos de causa y evaluación moral de dicho frame, encontramos que Rosalía "no cumple las reglas del género y desvirtúa la esencia jonda de los cantes" (García Reyes, $A B C$, 25 de noviembre de 2018) y “simplemente propone un tipo de flamenco que no pasa los controles mínimos de calidad” (García Reyes, $A B C$, 2 de octubre de 2018).

El uso de dicho vocabulario y expresiones constituyen elementos de frame que evidencian un posicionamiento y una evaluación moral respecto a la obra de Rosalía y las consecuencias dañinas de ésta para la tradición jonda. La creación de identidad (nosotros) mediante la definición de la alteridad (el otro) es un mecanismo básico en la construcción de colectivos (Luchetti, 2009); cuando este mecanismo se polariza, esto es, se realzan las cualidades superiores del endogrupo

8 Fechas extraídas de la teoría generacional de Strauss-Howe (Strauss y Howe, 1997: 176-177). 
(nosotros) y se excluyen las características del exogrupo (el otro extraño), es cuando asistimos a una dinámica típica de los discursos racistas (Van Dijk, 2016). Dado que “Los frames son utilizados para naturalizar y justificar ideologías” (Moernaut y Pauwels, 2017: 4), el frame de El invasor llama con urgencia al endogrupo (los amantes del flamenco y sus simpatizantes) a defender la pureza de la música flamenca.

A pesar de no emitir evaluaciones morales de forma directa, el medio El Mundo da cabida a este frame (aumentando la polifonía y cantidad de frames presentes en su discurso) resaltando dos declaraciones (elementos paratextuales) respecto a la música de Rosalía: "Rosalía tiene mucho talento pero su sitio no es el flamenco" (Cristina Heeren Citado en Moreno, El Mundo, 5 de febrero 2019), de Cristina Heeren, y “Lo que hace Rosalía no se puede llamar flamenco" (El Mundo, 25 de marzo de 2019), del cantaor José Mercé.

\section{4. - Universalismo cultural [Tema problemático] [counter-frame de “3. - El invasor”]:}

\section{Presente en: El País / El Mundo / La Vanguardia / ABC}

La definición de este tema problemático radica en la acusación esgrimida por parte del colectivo gitano contra la artista catalana, donde su condición de mujer paya con privilegios la sitúa como un referente negativo para la etnia gitana y la cultura flamenca. A diferencia de "El invasor", este frame se posiciona en defensa de Rosalía y el lema de "La cultura no tiene propietarios" (Rosalía citada en Fajardo, El Mundo: Metrópoli, 29 de junio de 2018).

Como elementos de frame prominentes señalamos el uso de las propias declaraciones de Rosalía resaltadas en subtítulos y dentro del cuerpo del texto (elementos paratextuales): "vivimos en un mundo global donde ya no existen los géneros" (Rosalía Citado en Fajardo, El Mundo: Metrópoli, 29 de junio de 2018). Esta perspectiva trata de inhabilitar la visión esencialista de la cultura así como los procesos fundamentalistas de exclusión/racismo que resultan de la polarización entre endogrupo (nosotros) y exogrupo (el otro extraño) patente en el frame“3. - El invasor” (Van Dijk, 2016) .

Si concebimos la diferencia cultural (p. ej.: ser gitano o payo) como un proceso identitario social e históricamente construido y oculto bajo la idea naturalizante de una "esencia" o biologización de la diferencia (McLaren, 1997: 147), entonces podemos comprender cómo "la diferencia aparece como un trabajo del poder incorporado por los propios excluidos" (Mbembe, 2016: 18). Siendo la necesidad de afirmar la pertenencia identitaria a un grupo (y por ende, la necesidad de excluir a todo individuo que quede fuera de esta categorización) un mecanismo de supervivencia que funciona como "el lenguaje invertido del deseo de reconocimiento e inclusión" (Mbembe, 2016: 321).

Como proposición de solución, este frame plantea la apreciación de la apropiación cultural como un acto intrínseco al proceso creativo y a la evolución cultural, argumento evocado mediante la cita de la famosa sentencia de Picasso: "Un artista copia y un gran artista roba" (Belmonte, $A B C$, 5 de febrero de 2019). En la era digital, la diferenciación esencialista entre grupos es sustituida por una caracterización más fluida de las tradiciones y culturas, dinámica que nos aleja cada vez más del inmovilismo cultural: "los conflictos étnicos surgen de hecho cuando las desigualdades étnicas y los sistemas articulados por criterios raciales empiezan a romperse. Y, sin duda alguna, una manera de evitar el conflicto, con tal de mantener un status quo dado, es la de recordar que hay diferencias" (Martí, 2000: 180). 


\section{5. - La liberadora de los oprimidos [Tema problemático]}

\section{Presente en: El País / El Mundo / La Vanguardia / ABC}

Bajo este frame se evoca a una figura femenina que guía a un colectivo oprimido hacia la emancipación. Es la figura alegórica que encontramos en la pintura La Libertad guiando al pueblo (1830) de Eugène Delacroix. El tema problemático aquí tratado es la patente falta de visibilidad y liderazgo femenino en el sector de la industria musical. Crítica que se alinea con la agenda de la cuarta ola de los movimientos de género: la denuncia pública contra la violencia sexual, el maltrato y los agentes opresores; la búsqueda de justicia y la solución urgente de una inconclusa proposición de paridad social (Sternadori, 2019). En palabras de la propia Rosalía: "Nunca voy a dejar de pelear hasta encontrarme el mismo número de mujeres que de hombres en el estudio, ¡menos mal que cada vez hay más!” (Sotillo, El Mundo - Yo Dona, 5 de enero de 2019 ). Bajo este frame, la artista catalana "simboliza una inaplazable feminización del negocio musical” (Neira, El País, 11 de Julio de 2019). Como elementos de causa se atribuye la temática narrativa y conceptual de El mal querer (la violencia de género y la liberación femenina), el liderazgo que la propia artista ejerce como artífice de su propia carrera y su papel como catalizadora de las voces de diversos colectivos $L G T B I Q+$ (su apoyo por parte del colectivo gay o su amistad pública con la actriz transgénero Hunter Schafer son ejemplos de ello). A fin de destacar a Rosalía como una figura alegórica de poder y libertad es utilizado un frame de acción (agency frame), el cual "refleja a un individuo activo que tiene fuerza, capacidad, una voz, liderazgo, poder y similares" (Lind y Salo, 2002: 221). En el caso de la cantante catalana, este encuadre es enfatizado a través del lenguaje, por ejemplo, el uso de palabras como liderazgo, pelear, lucha o la evaluación de su actitud: "Rosalía. Hembra. Empoderada. En órbita” (Martínez, El Mundo, 11 de noviembre de 2018). En adición, los cuatro medios mencionan a otros actores relacionados con la problemática que refuerzan dicho encuadre: Lauryn Hill, Björk, La Zowi, Chavela Vargas, Miley Cyrus, Lola Flores, Beyoncé o Soleá Morente, siendo todas mujeres referentes en la gestión de su propio proyecto artístico y en la lucha por la paridad dentro de la industria musical.

\section{6. - La obra de arte total}

\section{Presente en: El País / El Mundo / La Vanguardia / ABC}

El siguiente frame evoca el concepto de La obra de arte total (Das Gesamtkunstwerk) desarrollado por el compositor alemán Richard Wagner en sus diversas óperas y través de su obra La obra de arte del futuro (1849/2000). Esta concepción global de la performance artística nos sitúa, así mismo, bajo la concepción griega de la Mousiké: la unión en sinergia de diversas artes como la declamación, la poesía, la música, la interpretación teatral o el baile. De la misma forma, el universo que rodea a El mal querer (2018) de Rosalía y “su concepto total del espectáculo” (Zanón, La Vanguardia, 8 de diciembre de 2019) es evaluado bajo características como "sus vídeos de alta factura estética”, "los stories de Instagram donde ella misma analiza su obra” (Sotillo, El Mundo: Yo Dona, 5 de enero 2019), pasando por “las canciones, las coreografías vehiculizadas por ella y ocho bailarinas, el despliegue luminotécnico (no apabullante pero de una eficacia... deslumbrante) y un guión para los diferentes temas" (Linés, La Vanguardia, 16 de julio de 2018). Haciéndose patente cómo la artista catalana "ha proyectado una marca propia global" (Domènech, La Vanguardia, 25 de septiembre 2019) aliada con profesionales de 
otras áreas como las modistas como María Escoté, Palomo Spain o María Simún o el sello visual que la productora audiovisual Canadá ha depositado en la marca Rosalía.

La naturaleza intertextual del universo Rosalía deriva de la superposición de sus diversos papeles como compositora, intérprete, protagonista de sus videoclips y sujeto de la narrativa conceptual que se despliega en los once capítulos ${ }^{9}$ de El mal querer. A estas características podríamos añadir la vida privada de la artista y su solapamiento con su persona digital y mediática; conformando la diversidad y complejidad de estratos del yo presentes en el estrellato como fenómeno poliédrico (Dyer, 2004; Wolfheil et al., 2019). Actualizando el concepto wagneriano, la obra de arte total en la era digital mantiene uno de sus pilares fundamentales en el uso de las redes sociales (p. ej.: la comunicación parasocial entre estrellas y fans a través de plataformas como Twitter e Instagram), así como en el gusto por el formato audiovisual y la difusión de contenido en plataformas de streaming como YouTube o las efímeras stories de Instagram.

De tal forma, todos estos elementos actúan en sinergia contribuyendo a la formación de un nuevo lenguaje y una mitología generacional: Su "perenne coleta larga" (Mellado, $A B C$, 15 de febrero de 2019), "un nazareno con capirote y en monopatín, como la mezcla de lo racial con lo último" (referente al videoclip de Malamente) (Hidalgo, El País, 16 de julio de 2018), "su estilo chandalero, sus largas uñas de gel y su flamenco y trapeo agitanado y elegante" (El País, 6 de agosto 2019), o que "su 'tra trá' será patrimonio generacional" (Navarro, El País, 5 de noviembre de 2018), son elementos que reflejan el imaginario Rosalía y el carácter ramificado del estrellato en la era digital.

\section{7. - El producto de masas [tema conflictivo]}

\section{Presente en: $A B C$ / El Mundo}

Este frame culturalmente imbuido nos remite a la crítica sobre la cultura de masas y la industria cultural ejercida por Horkheimer y Adorno en Dialéctica del Iluminismo (1944/1988). Bajo esta mirada, el artista popular y su obra son concebidos como un producto creado para satisfacer a los consumidores y su debilidad por los fenómenos fugaces. A pesar del contexto interactivo que supone la era digital, no debemos descartar ciertos aspectos de continuidad respecto a la cultura de masas: en el caso de la industria cultural española, observamos una remanente inclinación a la trivialidad y uniformidad del gusto, la tendencia al entretenimiento pasivo o la estratificación de la producción cultural condensada en grandes grupos empresariales (Núñez-Ladevéze e Irisarri, 2014: 473).

En este ejemplo, la evocación de dicho marco es aplicado a Rosalía como artista perteneciente a la esfera mainstream. La inclusión de términos como "industria", "vorágines", "bisnes" y “tendencia a la futilidad” (Serrano, $A B C, 11$ de julio de 2019; $A B C$, 6 de julio de 2019), o la frase "la catalana decidió probar con este tipo de música empujada por su discográfica" (García Reyes, $A B C, 25$ de noviembre de 2018), enfatizan este tipo de lectura apocalíptica sobre la cultura de masas (Eco, 1984). Frente a otros encuadres que sitúan a la artista catalana como una figura con capacidad de liderazgo y acción

9 Para profundizar en esta naturaleza intertextual debemos señalar también cómo la trama argumental/musical de El mal querer mantiene una conversación con la anónima novela occitana Flamenca (1287). En su canal de YouTube, el conocido divulgador musical Jaime Altozano analizó esta relación entre análisis musical y contenido narrativo. Véase su vídeo "ROSALÍA: lo que nadie está diciendo sobre El mal querer". Véase: https://www. youtube.com/watch?v=NgHXFTgaVT0 
autónoma (ej.: "1.B - La heroína y su ejército" o “5. - La liberadora de los oprimidos"), este octavo frame considera la inclusión del fenómeno Rosalía como una mercancía cultural dentro del hegemónico sistema-mundo global del capitalismo (Wallerstein, 1979). Bajo esta perspectiva, Illescas Martínez (2011: 12) subraya el uso de la "autenticidad" o la "marca de origen" de los artistas como mera estrategia publicitaria fraguada por "los tentáculos de las majors" (Ibíd.: 223.). O en palabras del propio $A B C$ : "La industria que [Rosalía] aparentemente tiene en sus manos. Pero que no se engañe nadie: por mucho que un artista haya parecido tener al «bisnes» a su merced, eso jamás ha ocurrido (Serrano, $A B C, 11$ de julio de 2019).

\section{Discusión y conclusiones}

En conclusión, hemos comprobado el potencial heurístico que la aleación del análisis de framing narrativo y retórico (Van Gorp, 2010; Kuypers, 2010) guardan en esta pionera aplicación al estrellato y la música popular. Esta propuesta cualitativa e inductiva amplia las propuestas de framing en periodismo musical (McClain, 2016; McClain y Lascity, 2019) que, bajo la noción de los frames culturalmente imbuidos (Van Gorp, 2010), le otorga al análisis de encuadres una dimensión sociocultural más prominente y conectada con el contexto vivo. Tras el análisis del total de 331 artículos presentes en los periódicos El País, El Mundo, La Vanguardia y ABC, la extracción de sus respectivos frames y su relación con su contexto sociocultural profundo (cumplimiento del $\mathrm{O} 1 \mathrm{y} \mathrm{O}$, respectivamente), hemos hallado los siguientes frames culturalmente imbuidos:

En "1.A - El ídolo" se retrata a Rosalía como una figura semi-divina, constatando el carácter religioso y mitológico que adoptan las estrellas con el advenimiento del capitalismo tardío (Morin, 1972, Busquet-Duran, 2012). A través de un lenguaje épico y metáforas belicistas, en el frame "1.B - La heroína y su ejército", se reflejan las posibilidades de autonomía y liderazgo que alcanzan determinados artistas y sus equipos favorecidos por el ecosistema digital (Loy et al., 2018) y el fenómeno de la hipermediación (Carr, 2000). Este mismo contexto tiene como consecuencia la creciente globalización de lo local, donde el frame "1.C - La embajadora (de lo local a lo global)" valora positivamente la internacionalización de Rosalía como representante de lo español en el extranjero.

A través de "2.A - El artista revolucionario (tradición y modernidad)" " "2.B - el nexo generacional" vemos que Rosalía funciona, respectivamente, como sintetizadora dentro del modelo de propulsión artística (Sternberg, Kaufman y Pretz, 2001) y como puente entre la generación millennial y la tradición jonda. El encuadre "3. - El invasor (la muerte del flamenco)" utiliza la polarización como mecanismo para situar a Rosalía y otros artistas heterodoxos dentro de la categoría de falsos revolucionarios (exogrupo), los cuáles son calificados como una amenaza para la integridad del flamenco y sus amantes (endogrupo). En cambio, la perspectiva de “4. - Universalismo cultural” nos acerca a la idea de cómo toda diferenciación racial y "biologización” de ésta esconde un ejercicio de poder históricamente construido muchas veces incorporado por el propio grupo sometido (McLaren, 1997; Mbembe, 2016). Además, este último encuadre propone el acto de apropiación cultural como un paso necesario para el desarrollo creativo de las sociedades.

En quinto lugar, “5. - La liberadora de los oprimidos" se basa en un frame de acción o agency frame (Lind y Salo, 2002), pues retrata a Rosalía como una de las figuras encargadas de visibilizar la lucha de la mujer por la paridad en la industria musical. El encuadre "6. - La obra de arte total" evoca la idea wagneriana de las distintas artes en sinergia aplicadas al álbum 
de El mal querer (composición y producción, videoclips, diseño artístico, vestuario y maquillaje, RRSS, etc.). En último lugar, el frame "7. - El producto de masas" hace eco de la Escuela de Frankfurt en su concepción del artista como títere de la industria cultural y sus dinámicas: estandarización, trivialidad de los productos, producción seriada y el énfasis en la creación de bienes de entretenimientos destinados a un público pasivo y acrítico (Horkheimer y Adorno, 1944/1988).

De tal forma, constatamos la notable variedad de frames (un total de 10), siendo algunos de estos antagonistas dentro del mismo medio (p. ej: la presencia de "3. - El invasor" y sus counter-frames "4. - Universalismo cultural" y "2.A - El artista revolucionario [tradición y modernidad]” en $A B C$ y $E l$ Mundo). Esta polifonía presente en los cuatro medios confirma la complejidad y el carácter polimórfico del estrellato tal y como lo manifiesta la literatura académica de referencia (Dyer, 2004; Marshall y Redmond, 2015; Wolfheil et al., 2018). En su cualidad de receptáculos semióticos de significado cultural (Dyer, 1998), las estrellas "se erigen como espejos de los valores dominantes de un tiempo" (Busquet Duran, 2012: 13). Insertada en este marco y gracias a la extracción de los frames explicados, se explica por qué Rosalía cataliza una miríada tan rica de problemáticas actuales (confirmamos H2).

En última instancia, este artículo amplía las investigaciones sobre música en la cultura digital dentro del ámbito hispanohablante (Márquez, 2010; Hennion, 2010; De Aguilera, Adell y Borges, 2010; Illescas Martínez, 2014) desde el campo del periodismo, la teoría del framing y la comunicación social. Así mismo, cabe señalar que las limitaciones de este trabajo adscrito al análisis de la prensa escrita nacional dejan la puerta abierta a nuevas vías de investigación como son: el estudio de los frames en torno al fenómeno Rosalía en prensa musical especializada y medios internacionales, la aplicación del análisis de framing narrativo y retórico adaptado a otros formatos tradicionales (radio y televisión) y plataformas digitales (YouTube, TikTok o Instagram), o el estudio de otro fenómenos de masas y su relación con los valores, deseos, metáforas, miedos, arquetipos y narrativas culturalmente imbuidas de las sociedades posmasivas digitalizadas.

\section{Referencias bibliográficas}

Adler, M. (2006). «Stardom and talent». Handbook of the Economics of Art and Culture, 1, 895-906.

https://doi.org/10.1016/S1574-0676(06)01025-8

Álvarez, N. (14 de diciembre de 2019). La reina Rosalía. La Vanguardia, p. 10.

Arbat, S. (28 de agosto de 2019). Folklore con capa y corsé. La Vanguardia, p. 27.

Bateson, G. (1993). Una unidad sagrada. Pasos ulteriores hacia una ecología de la mente. Barcelona: Gedisa. (Versión original de 1972).

Belmonte, R. (5 de febrero de 2019). Desgitanizar. $A B C$, p. 12.

Benito, C. (13 de julio de 2019). BBK La apoteosis de Rosalía en Bilbao. $A B C, 46$.

Bryant, J. y Miron, D. (2004). Theory and Research in Mass Communication. Journal of Communication, 54: 662-704. doi:10.1111/j.1460-2466.2004.tb02650.x 
Busquet Duran, J. (2012). El fenómeno de los fans e ídolos mediáticos: evolución conceptual y génesis histórica. Revista de estudios de juventud, 96, 13-29.

Cabrera González, M. A. (2001). Convivencia de la prensa escrita y la prensa "on line" en su transición hacia el modelo de comunicación multimedia. Estudios sobre el Mensaje Periodístico, 7, 71-78.

Carr, N. (2000). Hypermediation: Commerce as Clickstream. Harvard Business Review, enero-febrero, 46-47.

Carrión, J. (Ed.). (2021). La Rosalía. Ensayos sobre el buen querer. Errata Naturae: Madrid.

Castells, M. (1997). El poder de la identidad, Vol. II. La era de la identidad. Economía, sociedad y cultura. Buenos Aires: Siglo Veintiuno Editores.

Castro, E. (2019). El trap. filosofía millennial para la crisis en España. Errata Naturae: Madrid.

Cusack, C. (2011). Celebrity, the Popular Media, and Scientology: Making Familiar the Unfamiliar. En J. R. Lewis (Ed.), Scientology (pp. 389-410). Universidad de Tromso, Noruega: Oxford Scholarship Online. doi: 10.1093/ acprof:oso/9780195331493.003.0021.

De Aguilera, M., Adell, J. E., y Borges, E. (2010) Apropiaciones imaginativas de la música en los nuevos escenarios comunicativos. Comunicar: Revista científica iberoamericana de comunicación y educación, 34, 35-44 (Ejemplar dedicado a: Música y pantallas: mediaciones en el nuevo escenario digital).

Del Barrio, A. (25 de marzo de 2019). La entrevista final. José Mercé. El Mundo.

Domènech, A. (28 de agosto de 2019). Rosalía sigue haciendo historia. La Vanguardia, p. 26.

(25 de septiembre 2019). Rosalía, un 'cumpleanys' con una historia de oro. La Vanguardia, p. 7.

Dyer, R. (1998). Stars. Londres: British Film Institute.

(2004). Heavenly Bodies: Film Stars and Society. Abingdon: Routledge.

Eco, U. (1984). Apocalípticos e integrados. Barcelona: Lumen.

Entman, R. (1993). Framing toward clarification of a fractured paradigm. Journal of Communication, 43(4), 51-58.

Erickson, Kira (2019). "Framing Feminism: How U.S. and French Media Frame \#MeToo and \#BalanceTonPorc from a Feminist Perspective". WWU Honors Program Senior Projects, 119.

Escribano, A. (11 de diciembre de 2019) Rosalía, bienvenidos al flamenco del siglo XXI. $A B C$, p. 65.

Fajardo, J. (29 de junio de 2018). «Hay una nueva generación que rompe fronteras». El Mundo - Metrópoli, p. 58.

Flamenca. (1287). Ed: Paul Meyer.

Firth, S. (1996). Music and identity. En S. Hall y P. Du Gay (Eds.), Questions of cultural identity (pp. 108-127). California: Sage Publications, Inc.

García Reyes, A. (30 de septiembre de 2018). Rosalía, cantante de flamenco. $A B C$, p. 83.

(2 de octubre de 2018). Reunión de fracasos históricos. $A B C$, p. 71. 
(25 de noviembre de 2018). Por qué Rosalía no es flamenca: un viaje del cante al pop. ABC, p. 58.

(6 de julio de 2019). Para caerse de culo. $A B C$, p. 12.

Gil, P. (30 de octubre de 2018). La ley de Rosalía. El Mundo - Papel, pp. 23-25.

Goffman, E. (1986). Frame analysis. An essay on the organization of experience. Boston: Northeastern University Press. (Versión original de 1972).

Hall. S. (2003). ¿Quién necesita identidad? En S. Hall y P. D. Gay (Eds.), Cuestiones de identidad cultural, (pp. 13-39). Buenos Aires : Amorrortu.

Harrison, C. (2018). Interstellar Songwriting: What Propels a Song Beyond Escape Velocity? En S. Loy, Popular music, stars and stardom (págs. 21-36). Australia: ANU Press.

Hennion, A. (2010). Gustos musicales: de una sociología de la mediación a una pragmática del gusto. Comunicar: Revista científica iberoamericana de comunicación y educación, 34, 25-33 (Ejemplar dedicado a: Música y pantallas: mediaciones en el nuevo escenario digital).

Hidalgo, 1. (16 de julio de 2018). El flamenco electrónico de Rosalía echa a volar en el Sónar. El País, p. 27.

Higuera, A. (17 de junio de 2019). Noche Blanca del Flamenco. ABC, p. 58.

Horkheimer, M. y Adorno, T. (1988). Dialéctica del iluminismo. Buenos Aires: Sudamericana. (Versión original de 1944).

Hormigos, J. (2010). Distribución musical en la sociedad de consumo. La creación de identidades culturales a través del sonido. Comunicar: Revista científica iberoamericana de comunicación y educación, 34, 91-98 (Ejemplar dedicado a: Música y pantallas: mediaciones en el nuevo escenario digital).

Igartua, J., Muñiz, C., Cheng, L. (2005). La inmigración en la prensa española. Aportaciones empíricas y metodológicas desde la teoría del encuadre noticioso. Revista Migraciones,17, 143181.

Illescas Martínez, J. E (2011). Las industrias culturales hegemónicas como generadoras de un nuevo concepto de "lo latino" en el sistema mundial: el caso del videoclip en la primera década del siglo XXI. Universidad de Alicante, Alicante.

Jenkins, H. (2006). Convergence culture. Where old and new media collide. Nueva York: New York University Press.

Jiménez-Yáñez, R. (2017). La representaciones de la religión en editoriales de cuatro periódicos españoles (2009-2010). Universidad de Navarra, Pamplona.

Kandinsky, V. (1979). De lo espiritual en el arte. México: Premia Editora S.A. Versión original de 1911.

Kuypers, J. A. (2010). Framing analysis from a rhetorical perspective. En P. D’Angelo y J. A. Kuypers (Eds.), Doing new framing analysis: Empirical and theoretical perspectives (pp. 286-311). New York, NY: Routledge.

La aristocracia del pop se da cita en la gala de Fibes. (3 de noviembre de 2019). ABC, p. 75.

Lakoff, G. y Johnson, M. (1981). Metaphors we live by. Chicago: University of Chicago Press.

Linés, E. (16 de julio de 2018). Rosalía deslumbra en el Sónar con su arte de raíz. La Vanguardia, p. 41. 
Lind, R. y Salo, C. (2002). The Framing of Feminists and Feminism in News and Public Affairs Programs in U.S. Electronic Media. Journal of Communication. 52. DOI: 211 - 228. 10.1111/j.1460-2466.2002.tb02540.x.

López Enano, V. (16 de septiembre de 2018). Rosalía, viaje del flamenco al trap. El País - Semanal, pp. 5 y 30-37.

Loy, S., Rickwood, J., y Bennett, S. (2018). Popular music, stars and stardom. Australia: Australian National University Press. Luchetti, M. F. (2009). La alteridad como configuradora de la identidad. V Jornadas de Jóvenes Investigadores. Instituto de Investigaciones Gino Germani, Facultad de Ciencias Sociales, Universidad de Buenos Aires, Buenos Aires.

Macrossan, P. (2018). Intimacy, Authenticity and 'Worlding' in Beyoncé's Star Project. En J. R. Stephen Loy, Popular music, stars and stardom (págs. 137-152). Australia: Australian National University Press.

Márquez, i. V. (2010). Hipermúsica: la música en la era digital. TRANS, 14 (2010).

Marshall, P. D. (2010). The promotion and presentation of the self: Celebrity as marker of presentational media. Celebrity Studies, 1 (1), 35-48. https://doi.org/10.1080/19392390903519057

Marshall, P. y Redmond, S. (2015). Celebrity intersections. Road, Paths, Fields, and Landscapes. En P. D. Marshall y S. Redmond (Eds.), A Companion to Celebrity (pp. 1-13). Sussex: John Wiley \& Sons.

Martí, J. (2000). Más allá del arte. El arte como generadora de realidades sociales. San Cugat del Vallès: Deriva Editorial.

Martínez, R. (11 de noviembre de 2018). Rosalía en órbita. El Mundo, p. 15.

Mbembe, A. (2016). Crítica de la razón negra. Ensayo sobre racismo contemporáneo. Barcelona: Futuro Anterior Ediciones.

McClain, J. (2016). Framing in Music Journalism: Making Sense of Phish's “Left-Field Success Story”. The Journal of Popular Culture. 49. 1206-1223. 10.1111/jpcu.12489.

McClain, J. y Lascity, M. (2019). Toward the Study of Framing Found in Music Journalism. Popular Music and Society. 43. 1-14. 10.1080/03007766.2019.1581899.

McLaren, P. (1997). Pedagogía crítica y cultura depredadora. Políticas de oposición en la era posmoderna. Barcelona: Paidós educador.

Mellado, A. (15 de febrero de 2019). Rosalía, entre los jóvenes más influyentes de Europa. $A B C$, p. 76.

Moernaut, R., y Pauwels, L. (2017). Framing Climate Change: A Multi-level Model. Handbook of Climate Change Communication, vol: 1. DOI: 10.1007/978-3-319-69838-0_14.

Morán, D. (8 de diciembre de 2019). Una Rosalía pletórica conquista a lo grande su primer Sant Jordi. ABC, p. 59.

Moreno, I. (2002) La globalización y Andalucía. Entre el mercado y la identidad. Sevilla: Mergablum.

Moreno, S. (5 de febrero de 2019). La entrevista final. Cristina Heeren. El Mundo.

Morin, E. (1972). Las stars. Servidumbres y mitos. Barcelona: Dopesa.

Navarro, F. (5 de noviembre de 2018). La gala MTV, una apuesta por dejar alucinado al público. El País, p. 28.

Neira, F. (18 de enero de 2018). Rosalía, Premio Ruido. El País, p. 8. 
(11 de Julio de 2019). Rosalía se instala en la hipérbole. El País, p. 5.

Núñez-Ladevéze, L. e Irisarri, J. A. (2015). Industria cultural y relaciones 'cara a cara' en las redes: la continuidad del cambio en España. Estudios sobre el Mensaje Periodístico, 21(1), 471-490. https://doi.org/10.5209/rev_ESMP.2015.v21. n1.49106

Peirón, F. (17 de noviembre de 2018). Las Vegas corona el flamenco catalán. La Vanguardia, p. 36.

(1 de mayo de 2019). ¿Beyoncé? Nooo, Rosalía. La Vanguardia, p. 32.

Polletta, F. (2004). Culture is not just in your head. En J. Goodwin, y J. M. Jasper (Eds.), Rethinking social movements: Structure, meaning, and emotion (pp. 97-110). Nueva York: Rowman and Littlefield.

Redmond, S. (2015). Part six. Emotional celebrity. En P. D. Marshall y S. Redmond (Eds.), A Companion to Celebrity (pp. 351-354). Sussex: John Wiley \& Sons.

Reese, S. (2001). Framing public life: A bridging model for media research. En S. Reese, O. Gandy, \& A. Grant (Eds.), Framing public life (pp. 7-31). Mahwah, NJ: Erlbaum.

Rigalt, C. (10 de febrero 2019). Rosalía, flamenca, que no charnega. El Mundo.

Rizo García, M. (2013). Comunicación interpersonal digital y nuevas formas de comunidad. Reflexiones sobre la comunicación pos-masiva. Imagonautas: revista interdisciplinaria sobre imaginarios sociales, 3 (2), 52-65.

Rojek, C. (2001). Celebrity. Londres: Reaktion Books.

Rosalía se convierte en chica de calendario para Pirelli. (6 de agosto 2019). El País, p. 27.

Rosalía, 'santificada' en el Fossar de les Moreres. (10 de enero de 2019). La Vanguardia, p. 32.

Rosen, S. (1981). The economics of superstars. The American Economic Review, 71 (5), 845-858.

Sabrina Koziner, N. (2013). Antecedentes y fundamentos de la teoría del framing en comunicación. Austral Comunicación, 2 (1), 1-25.

Sádaba, T. (2001). Origen, aplicación y límites de la "teoría del encuadre" (framing) en comunicación. Comunicacion y Sociedad, 14(2), 143-175.

Serrano, N. (11 de julio de 2019). Rosalía, el juguete irrompible se come el arranque del Mad Cool Festival. ABC, pp. 44-45. (30 de octubre de 2018). «Para mí el flamenco no es un fin ni un medio: lo es todo, es mi vida». $A B C$, p. 53.

(31 de agosto de 2019). En la corte de Rosalía. $A B C$, pp. 55-56.

(12 de septiembre de 2019). El regreso de «The Face», la última gran revista musical. $A B C$.

Solís Baena, J. (2016). La evolución de los periódicos digitales frente a los convencionales como soporte publicitario. Universidad Complutense de Madrid.

Sotillo, M. (5 de enero de 2019). Rosalía, objetivo conseguido. El Mundo - Yo Dona, pp. 1 y 28-29.

Sternadori, M. (2019). Situating the Fourth Wave of feminism in popular media discourses. En Misogyny and Media in the Age of Trump, 31-55. 
Sternberg, R. y Kaufman, J. y Pretz, J. (2001). The Propulsion Model of Creative Contributions Applied to the Arts and Letters. The Journal of Creative Behavior. 35. 75-101. 10.1002/j.2162-6057.2001.tb01223.x.

Strauss, A. L. y Corbin, J. (1990). Basics of qualitative research: Grounded Theory procedures and techniques. Newbury Park, CA: Sage.

Strauss, W. y Howe, N. (1997). The fourth turning. An american prophecy. Nueva York: Broadway Books.

Tankard, J.W. (2001). The empirical approach to the study of media framing. En S.D. Reese, O.H. Gandy, \& A.E. Grant (Eds.), Framing public life. Mahway, NJ: Lawrence Eribuam, 95-106.

Van Dijk, T. A. (2016). Estudios Críticos del Discurso: Un enfoque sociocognitivo. Discurso \& Sociedad, Vol. 10(1), 167-193.

Van Gorp, B. (2010). Strategies to take subjectivity out of framing analysis. En: D’Angelo P., Kuypers J. (Eds.), Doing news framing analysis: Empirical and theoretical perspectives. New York: Routledge, 84-109.

Van Gorp, B. y Vercruysse, Tom. (2012). Frames and Counter-Frames Giving Meaning to Dementia: A Framing Analysis of Media Content. Social science \& medicine (1982). 74. 1274-81. 10.1016/j.socscimed.2011.12.045.

Vasilachis de Gialdino, I. (2006). Estrategias de investigación cualitativa. Barcelona: Gedisa.

VEVO, (2015). Vevo Music Fan Report: The Millennial Fan Tribes. Recuperado de https://bit.ly/3hia3ha

Vox Populi. (5 de marzo de 2018). El Mundo, p. 20.

Wagner, R. (2000). La obra de arte del futuro. Valencia: Universitat de València. (Versión original de 1849).

Wallerstein, I. (1979). El moderno sistema mundial I: La agricultura capitalista y los origenes de laeconomia-mundo europea en el siglo XVI. México D.F: Siglo XXI.

Wohlfeil, M., Patterson, A. y Gould, S.J. (2019). The allure of celebrities: unpacking their polysemic consumer appeal. European Journal of Marketing, vol. 53 No. 10, pp. 2025-2053. https://doi.org/10.1108/EJM-01-2017-0052

Zanón, C. (8 de diciembre de 2019). Rosalía de todos, Rosalía de nadie. La Vanguardia, p. 43. 